\title{
APATÍA POLÍTICA Y MELANCOLÍA EN CARO MICHELE DE NATALIA GINZBURG
}

Political apathy in Caro Michele by Natalia Ginzburg

\author{
MARÍA BELÉN CASTANO \\ Universidad de Buenos Aires-CONICET (Argentina) \\ belcastano@gmail.com
}

Resumen

La novela epistolar Caro Michele [1973], de Natalia Ginzburg (1916-1991), aborda, como varias de las obras tardías de la autora, la decadencia de la pequeña burguesía y de la estructura tradicional de familia. Desarrollaremos la presencia de la melancolía en la novela ligada a su componente crítico. También nos proponemos analizar una reflexión acerca del lugar que ocupa la militancia del protagonista y la política como un objeto de deseo perdido en la obra.

Palabras clave: Natalia Ginzburg; melancolía; alienación; clases medias.

Abstract

Natalia Ginzburg's (1916-1991) epistolary novel Caro Michele [1973] addresses, like several of the late works of the author, the decadence of the petty bourgeoisie and the crisis of the traditional institution of the family. We will develop the presence of melancholy in the novel linked to its critical component. We also propose to analyze the place that occupies the protagonist's militancy and politics as an object of lost desire in the novel.

Key words: Natalia Ginzburg; melancholy; alienation; middle classes.

Caro Michele [1973] es la primera novela de Ginzburg perteneciente al subgénero epistolar; diez años después de la aparición de esta obra, la autora publica dos novelas epistolares, La famiglia Manzoni [1983], y al año siguiente, La città e la casa [1984].

La obra está centrada en la historia de una familia romana pequeñoburguesa que se intercambia cartas a raíz de la partida al exterior del hijo más joven. Ginzburg propone una narración que permite testimoniar tanto la decadencia del microcosmos del mundo pequeñoburgués, como el deterioro de la familia tradicional de la época de producción de la obra. La propuesta de analizar la presencia de la melancolía en Caro Michele permite explorar cómo el tedio y el pesimismo son características predominantes de sus protagonistas, cuya mirada crítica da cuenta de aquella pérdida de sentido que atraviesa las relaciones sociales dentro del contexto histórico en el que la obra está ambientada: los años setenta en Italia. Allí se contrapone, en primer lugar, a una generación de adultos con desilusión y apatía política $\mathrm{y}$, en segundo lugar, a una juventud con algún grado de compromiso político, que mantiene la esperanza por un porvenir diferente. Este es el caso de la militancia antifascista de Michele y de sus amigos, en oposición al sentido de derrota 
de la mayoría de los adultos que los rodean. Nuestra hipótesis de análisis se basa en que es posible pensar que más allá de la militancia de Michele, en la obra predomina una indiferencia hacia la política en general, que permite distinguir en la narración una melancolía dirigida a un objeto de deseo perdido, es decir: la creencia en un horizonte político futuro por el que valga la pena comprometerse, que muestra signos de agotamiento. Esta melancolía no se cristaliza explícitamente en una toma de conciencia respecto de este objeto de deseo perdido por parte de personajes particulares, sino en la imposibilidad de darle un sentido a sus vidas.

Michele, el destinatario de la mayoría de las cartas, es un joven de veinte años que parte a Londres de forma imprevista por motivos políticos. Los protagonistas que le escriben son su madre Adriana, su hermana Angélica, su amiga Mara, con la que pudo haber tenido un hijo y Osvaldo, su amigo y probable amante.

La novela está dividida en cuarenta y dos secciones, en las que se intercambian treinta y siete cartas y nueve segmentos narrativos. Un rasgo formal de esta obra es que se trata de una novela epistolar en la que la figura de un narrador impersonal se alterna con las cartas. En los segmentos narrativos, la obra presenta un narrador omnisciente neutral en tercera persona que no permite un control sobre el punto de vista del relato. En algunos capítulos se presentan diálogos en los que discursos y acciones se muestran de modo directo, sin intermediaciones de un narrador.

El arco temporal de Caro Michele abarca desde el día del cumpleaños número cuarenta y tres de la madre de Michele en noviembre de 1970, hasta el 9 de septiembre de 1971. Mientras Adriana le escribe ocho cartas a su hijo, él le contesta solo dos. La que recibe la mayor cantidad de cartas de Michele es Angélica, su hermana, con la que tiene una relación de mayor cercanía. Michele les escribe una carta a Mara y otra a Osvaldo. Además, se verifica un intercambio de cartas entre los otros personajes, que se vinculan entre sí a raíz de la partida de Michele.

\section{EL CARÁCTER TESTIMONIAL DE LA OBRA Y “LOS AÑOS DE PLOMO”}

Caro Michele es una obra que por su trama y por la fecha en la que está ambientada, se vincula directamente con el contexto histórico de los años setenta en Italia: un período en el que convivieron diferentes movimientos en los que la violencia política tuvo una particular intensidad. Fueron definidos como los "años de plomo", así como lo indica la película de la directora alemana Margarete von Trotta: Die bleierne Zeit [1981], en relación no solo con el clima político-social metafóricamente plomizo, sino sobre todo a partir del material de los proyectiles usados para cometer atentados ${ }^{1}$.

\footnotetext{
${ }^{1}$ Varios son los hechos que marcaron esta época, cuyos conflictos principales se inician con el atentado de Piazza Fontana el 12 de diciembre de 1969 en Milán, en el que más de un centenar de personas mueren a causa 40 | Alpha No49 (DiciEMBRE 2019) PÁGS. 39-56. ISSN 07 16-4254
} 
Resulta llamativo que en una obra como Caro Michele, en la que el protagonista está vinculado a una militancia antifascista, prevalece, de todos modos, un desinterés por parte de casi todos los personajes hacia la política en general. Más bien, lo que profundizaremos a continuación es cómo esa indiferencia política podría testimoniar una supuesta neutralidad ideológica, representativa de las clases medias. Al mismo tiempo, es posible explorar una convergencia entre este desinterés político generalizado y el rechazo por el contexto de violencia de los atentados. Así como indica Crainz, que sostiene que a lo largo de la década del setenta también se producen cambios que llevan a un distanciamiento de las motivaciones que habían exacerbado el conflicto político desde las décadas del sesenta, y ya a fines de los setenta se verifica en la sociedad italiana cada vez más un rechazo de la política (2016, p.154). Es por ello que resulta significativo que en novelas más tardías de Ginzburg como Famiglia [1977] y La città e la casa [1984], a diferencia de Caro Michele, ya no hay ningún personaje que esté vinculado a la militancia y son casi nulas las referencias a la política y al contexto histórico, sino que prevalecen más bien temáticas propias de los espacios domésticos: las casas y las familias de la pequeña burguesía ${ }^{2}$. Este rasgo se diferencia de obras anteriores como Tutti i nostri ieri [1952], Le voci della sera [1961] o Lessico famigliare [1963], en las que sus tramas están impregnadas de personajes que se involucran activamente en política con una militancia antifascista. Al contrario, casi todos los personajes de las obras tardías de Ginzburg, incluidas las obras de teatro, se desvinculan completamente de la militancia y se comprueba más bien un clima de indiferencia hacia la política en general. De hecho, Ginzburg le atribuye al personaje de Michele el rasgo principal de la duda que permea sus convicciones, como sostiene en una entrevista realizada por Walter Mauro (1986, p.66), en la que afirma que en Caro Michele se encuentra aquella incertidumbre que observa en la juventud de los años setenta: "Michele es un personaje del 68. No es un

\footnotetext{
de atentados y represión y otros miles son heridos, sobre todo en los primeros años "del escuadrón y de la masacre neofascista" y luego del terrorismo de izquierda de los años de plomo (Crainz, 2016, p.153). Durante esos años, maduran conquistas sociales que habían crecido en los años sesenta, con una amplia realización de la Constitución gracias a la progresiva abolición de normas y códigos heredados del fascismo, todos ejes que el neofascismo intenta desarticular. Entre ellos se destacan: la reducción del derecho de voto a los 18 años, la ley sobre el divorcio, la ley sobre el derecho de familia, una reglamentación sobre el aborto que pone el fin a las prácticas clandestinas, la reforma sanitaria, la reforma de las cárceles y de los hospitales psiquiátricos. Estos elementos se plasman en el contexto de Caro Michele, obra en la que se tematizan dichas conquistas: la ley sobre el derecho de familia y el divorcio se abordan con la separación de los padres de Michele y el tema de la legalización del aborto, cuya ley se promulga recién en 1978, se encarna en la oferta de dinero que Michele le hace a Mara para abortar, presumiblemente o de modo clandestino o en el exterior.

${ }^{2}$ Es importante destacar que las obras señaladas de la producción tardía están ambientadas en la época de su producción de las mismas.
} 
terrorista, no lo pensé como un terrorista, sino como un incierto, uno de estos jóvenes inciertos que giran por el mundo"3.

El carácter testimonial de esta novela epistolar, que la misma Ginzburg declara en las entrevistas con Walter Mauro (1986, p.67), es ampliamente abordado por la crítica literaria respecto de la autora, que señala el protagonismo que cobra aquí la tematización en la crisis de la pequeña burguesía y de las instituciones políticas italianas en la época de su producción. Para Sanvitale (1986, p.37), en Caro Michele se evidencia una estructura narrativa que tiene una coincidencia sintomática con las modificaciones en el modo de abordar la realidad de la autora misma en el período de producción de la obra. Una realidad que se torna incomprensible para la generación de Ginzburg, y que Sanvitale identifica en el hecho de que el ángulo del que narra, antes tan preciso y sin incertidumbres, se vuelve dudoso; cobra relevancia de este modo, según Sanvitale, una necesidad de escamotage para coordinar los mensajes, plasmada en el género epistolar (1986, p.37). Clementelli (1977, p.91) sostiene que Caro Michele representa el reflejo de la crisis de la sociedad italiana en los años sesenta y pone en primer plano un mundo alienado y disperso. Según Borri (1999, pp.61-62), en esta novela cobran protagonismo la ausencia, la tristeza y las frustraciones vinculadas a la crisis de la pequeña burguesía en la época de su producción. Borri considera a Caro Michele como el anti-Lessico famigliare, ya que aquí la familia no solo no tiene un léxico reconocible y doméstico que funcione como núcleo de unión, sino que lo que prima es el anonimato de varios personajes movidos por una carga melancólica (1999, p.63). Para Peja (2009, p.127-128), a pesar de la celebridad de Ginzburg, la engañosa simplicidad de su escritura muchas veces ha impedido una comprensión profunda de sus análisis y su estilo; y destaca que en la comicidad de sus textos, se exponen aparentes trivialidades que dan cuenta de la capacidad de la autora para comprender con lucidez su época.

\section{PESIMISMO Y MELANCOLÍA EN LA ENSAYÍSTICA DE GINZBURG CONTEMPORÁNEA A CAROMICHELE}

Es signifcativo destacar que la crítica implícita a la existencia alienada del capitalismo tardío, que subyace en las elaboraciones acerca de la melancolía en Ginzburg, se puede advertir en la marcada impronta autobiográfica que permea toda la producción de la autora. En efecto, su vida estuvo signada por el activismo antifascista, por su paso por el Parlamento italiano como diputada del Partido Comunista independiente en 1983 y por sus colaboraciones periodísticas, en especial en el diario del PC italiano L'Unità.

\footnotetext{
${ }^{3}$ A menos que se indique lo contrario, las traducciones del italiano al castellano de Natalia Ginzburg son mías. En italiano: "Michele è un personaggio del 68. Non è un terrorista, non l'ho pensato come terrorista, ma un incerto, uno di questi ragazzi incerti che girano per il mondo".

42 | AlPha No49 (DiCIEMBRE 2019) PÁGS. 39-56. ISSN 07 16-4254
} 
De ahí que sea posible analizar el carácter pesimista y melancólico de la producción de la autora de Lessico famigliare que ofrece una mirada crítica frente a un optimismo ligado al progreso y a la primacía de una visión persistente en la que el sufrimiento del ser humano se vincula con la pérdida de los lazos de comunidad de las sociedades tradicionales y con el peso derivado de la soledad y el anonimato que sufren los habitantes de las grandes ciudades modernas.

Nos detendremos, brevemente, en delinear el pesimismo por parte de Ginzburg en lo que se refiere a la ensayística contemporánea a Caro Michele, en su análisis del contexto histórico de la sociedad italiana postindustrial de los años setenta. En estos ensayos, el individualismo y la falta de esperanza por un futuro más justo son puestos a la luz como condiciones sin retorno. Es así que en "Vita colletiva" incluido en Mai devi domandarmi [1970] sostiene, en su vejez, que su época le inspira odio y aburrimiento, ya que la caracteriza como una etapa en la que se venera la existencia colectiva y no se tolera el pensamiento individual; un período considerado como "un melancólico y estéril producto de la soledad y del cansancio", una época, en la que "dos cosas son hoy odiadas y repudiadas con prepotencia, el cansancio y la soledad"5 (2002, p.109).

De la mano de una crítica generalizada de Ginzburg a los mecanismos utilitaristas del capitalismo tardío, se identifica una melancolía por un pasado en el que se veneraban la fatiga, el esfuerzo, la introspección y el pensamiento solitario, todas cuestiones que para ella habrían sido reemplazadas por la veneración del instante presente, la dispersión de los grupos y la primacía de un modelo de eterna adolescencia en busca de constantes libertades: por una humanidad a la que considera que "busca en el presente no una frágil felicidad, que no sabría cómo usar al no poseer ni fantasía ni memoria, sino más bien una sensación fugaz de supervivencia y de elección"6 (2002, p.112).

Otro ensayo representativo de este pesimismo es "Un governo invisibile", incluido en Vita immaginaria [1974], en el que se exploran motivos personales vinculados a la búsqueda de una definición posible de su relación con la política y de qué significa expresarse políticamente. También se examinan los diferentes papeles de los gobiernos contemporáneos. Ginzurg se autodefine como una persona con poca capacidad para comprender la política: "aunque no comprendo nada de política, me sucede a veces de encenderme de odio o de indignación, o de consenso y pasión por hechos políticos"7 (1974, p.170). Y se compara con otras personas que la rodean y a su juicio saben de

\footnotetext{
4" [U]n malinconico e sterile frutto di solitudine e di fatica".

5 "[D]ue cose sono oggi con prepotenza odiate e ripudiate, la fatica e la solitudine".

"6"[C]erca nel presente non una fragile felicità, che non saprebbe come usare non possedendo né fantasia né memoria, ma invece una fulminea sensazione di sopravvivenza e di scelta".

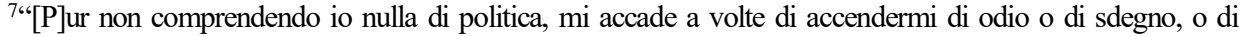
consenso e passione per fatti politici".
}

AlPHA No 48 (Julio 2019) PÁGS. 39-56. ISSN 07 16-4254| 43 
política; con la fe, sin embargo, en creer en determinadas ideas que le generan pasión, como las que evoca mediante un recuerdo de cuando tenía siete años y escucha por primera vez hablar de socialismo:

Me explicaron que era el socialismo, es decir me dijeron que era igualdad de bienes e igualdad de derechos para todos. Me pareció una cosa que era indispensable realizar en seguida. Encontré extraño que algo así no se hubiese hecho todavía. [...] Todavía hoy eso tiene el poder de despertar en mí una suerte de fuego ${ }^{8}$ (Ginzburg, 1974, p.170).

De este modo, en este ensayo Ginzburg recae en una nostalgia de un pasado en el que se apostaba al futuro: "pero nadie puede creer más en el futuro. Años atrás, todavía se podía, la música del mañana sonaba en nuestros oídos embriagante y verdadera. Sin embargo, repentinamente los siglos futuros se han desmoronado delante de nuestros pies" $^{\prime \prime}(1974$, p.173).

\section{LA MELANCOLÍA COMO COMPONENTE CRÍTICO}

¿De qué modo cabría relacionar la melancolía con su componente crítico? ¿Por qué los grandes creadores se encuentran entre los hombres melancólicos? La pregunta de Aristóteles en el Libro $X X X$ de sus Problemata se halla en el origen de una extensa y fecunda literatura que se ha interrogado respecto de las relaciones entre melancolía y creatividad. Este interrogante acerca del vínculo entre la melancolía y el genio creativo que plantea Aristóteles fue un tema abordado en Saturno y Melancolía [1964] de Klibansky/ Panofsky y Saxl ${ }^{10}$, cuya influencia se podría rastrear en el Origen del Trauerspiel alemán, ya que Walter Benjamin pudo leer lo que fue presentado como un estudio de la Biblioteca Warburg en 1923 y en su primera edición en alemán, que aparece con el título Dürers Melencolía I. Eine Quellen- und Typen-Geschichtliche Untersuchung.

En el estudio del Trauerspiel, presentado por Benjamin en 1925 para la habilitación a la docencia universitaria y publicado tres años más tarde a pesar del rechazo

\footnotetext{
8 "Mi fu spiegato cos'era il socialismo, cioè mi fu detto che era uguaglianza di beni e uguaglianza di diritti per tutti. Mi parve una cosa che era indispensabile fare subito. Trovai strano che ciò non fosse ancora stato attuato. [...] Ancora oggi essa ha il potere di svegliare in me una sorta di fuoco".

9 "Però nessuno riesce più a creder nel futuro. Anni fa, ancora ci si riusciva, la musica del domani suonava alle nostre orecchie inebriante e vera. Ma ad un tratto i secoli futuri ci sono crollati davanti ai piedi".

${ }^{10}$ Los autores sostienen también cómo esta melancolía moderna se vincula esencialmente con una conciencia intensificada de uno mismo, porque el yo es el eje en torno al que gira la esfera de la alegría y del dolor. A estas reflexiones del siglo XV se añadieron, además, todas las ideas originalmente ligadas a la melancolía y a Saturno: el amor desdichado, la enfermedad y la muerte. Se afirma aquí que esta trágica conciencia del yo no es otra cosa que un correlato de la conciencia de muerte (Klibansky, Panofsky, y Saxl 1991, págs. 229-230).

44 | Alpha No49 (DicIEMBRE 2019) PÁGS. 39-56. ISSN 07 16-4254
} 
de su solicitud, cobra particular relevancia un análisis concerniente a un pesimismo existencial dado por un desconsuelo terrenal y en el que se destaca la recuperación de las alegorías barrocas como una forma de expresión para comprender una realidad fragmentada ${ }^{11}$.

$\mathrm{Si}$ en los dramas del barroco las imágenes conforman representaciones emblemáticas de ideas y se rescata el valor artístico de la alegoría en su capacidad para comprender una realidad hecha de fragmentos, lo mismo se puede encontrar en la novela de Ginzburg aquí analizada, en especial en las pinturas del padre de Caro Michele. En la novela, la dispersión de objetos casuales cobra una significación relevante en la narración y se asiste a una búsqueda de significaciones y sentidos en aquellos objetos más banales.

¿Por qué vincular melancolía con una actitud crítica? Así como se señaló al principio de este trabajo, la melancolía puede considerarse afín a la actitud del descontento, del disconforme con el optimismo de los defensores que abogan por un progreso de la humanidad y está ligada a la actitud del desenmascaramiento. Es posible advertir en Caro Michele una visión pesimista vinculada a la melancolía, de la que se desprende una crítica a la pequeña burguesía y a la sociedad de masas, cuyo refugio, al contrario de lo que analiza Benjamin para los poetas barrocos alemanes, no se ubica en las certezas de la religión, sino en el escape al tedio que representa el mundo del entretenimiento de la sociedad de masas. Es mediante esta actitud de escapatoria que podemos ubicar también la apatía política y falta de interés por el entorno social de la pequeña burguesía que esta novela pone a la luz.

\section{MELANCOLÍA Y ALIENACIÓN}

La función crítica de la melancolía como un síntoma ligado al tedio de la cultura de masas se puede vincular, en parte, con la denuncia, implícita, en Caro Michele, por el carácter alienado que atraviesan las relaciones de los personajes, como indican los análisis antes mencionados de Clementelli (1977) y de Borri (1999). Asimismo, el estudio de Puppa (1986, p.108) advierte un clima general en Caro Michele netamente saturnino: nadie cree en la felicidad y ninguno aspira a ella.

\footnotetext{
${ }^{11}$ Es posible profundizar un análisis pertinente a la melancolía, la alienación y el tedio en la modernidad a partir de la obra Origen del Trauerspiel alemán, cuyo vínculo con la acedia y la ambivalente figura de Satán advertiría, para Miguel Vedda, una relación entre "la Modernidad secularizada y el espacio infernal", que asumiría en los trabajos posteriores de Benjamin una fuente de crítica de los tormentos del mundo del trabajo (2012, p.50). Asimismo, como señala Buck Morss, es posible encontrar una distancia crítica que Benjamin adopta en su trabajo de los pasajes respecto de la alegoría barroca del Trauerspiel (1995, p.193). Para Buck Morss, más allá de la reivindicación de los poetas alemanes barrocos que Benjamin subraya en su estudio, es posible encontrar un desprecio hacia una actitud subjetivista e idealista por parte del barroco alemán, ya que detrás del refugio en Dios se esconde una desvinculación de la política (1995, p.189).
} 
Si bien la bibliografía crítica acerca de la autora es amplia, no hemos localizado un estudio que analice exhaustivamente la presencia y la función que cumple la melancolía en su obra y la importancia que ella tiene, destacando su relación con la crisis del sujeto moderno y la alienación de la modernidad.

¿De qué manera se puede relacionar la melancolía con la alienación? En el análisis realizado por Marx en los Manuscritos económico-filosóficos (1844) se destaca que, con la instauración del trabajo alienado, el trabajador se pierde a sí mismo y pierde, a la vez, su ser genérico (Gattungssein) y su esencia genérica (Gattungswesen). Aun cuando la melancolía se puede relacionar puntualmente con trastornos y perturbaciones mentales, nos proponemos aquí indagar el vínculo que se desprende de la novela de Ginzburg entre la melancolía y la pérdida de la esencia genérica humana en la vida cotidiana bajo el capitalismo $^{12}$. Es posible advertir la reflexión de Marx de Los Manuscritos en Caro Michele, a partir de una descripción de los grupos sociales presentes en la obra, que expresan conflictos del momento histórico aquí retratado, en personajes abatidos por un sentido de derrota, en los que la melancolía cumple una función de cuestionamiento de una existencia alienada.

Ocupa un lugar central en la obra el protagonismo de personajes que pertenecen a la pequeña burguesía de Roma. Ellos disponen de un tiempo libre que les permite dedicarse a actividades ociosas y de goce estético como la pintura, la lectura y la jardinería. No obstante, el ocio, en lugar de ser una fuente de placer se convierte en causa de su melancolía. La falta de ocupaciones y el tiempo libre hacen que se encierren en pensamientos, incrementen su aislamiento, la falta de comunicación y la carencia de sentido en sus vidas. Los personajes que conforman este grupo son los padres de Michele, Ada, la exesposa de Osvaldo, y su amigo Fabio Collarosa, dueño de una editorial. Por otro lado, encontramos personajes que cumplen tareas serviles, como Cloti, que trabaja como empleada doméstica en la casa de la madre de Michele y Enrico, que trabaja como sirviente en la casa del padre de Michele. Estas figuras no cumplen roles protagónicos en la obra y sus voces ponen a la luz quejas constantes de las penurias por las que atraviesan y por los trabajos que realizan. Además, el conflicto entre estos dos grupos antagónicos se expresa en las declaraciones de la familia de Michele, que denotan cierto desprecio

\footnotetext{
${ }^{12} \mathrm{El}$ análisis de Marx respecto de la alienación (Entfremdung) y la enajenación (Entäußerung) del trabajador nos permite reflexionar acerca de la elaboración, en Caro Michele, de la falta de realización de sus personajes marcados por el tedio. En primer lugar, Marx destaca que la alienación "no se muestra solo en el resultado, sino el acto de producción dentro de la propia actividad productora" y entiende que en ese mismo acto de producción, el trabajador también se aliena a sí mismo (2015: p. 109). Cuando Marx se refiere a la enajenación del trabajo, observa que "el trabajo es externo al trabajador, es decir: no pertenece a su esencia; consiste, por ende, en que el trabajador no se afirma en su trabajo; sino que se niega; en que no se siente bien, sino desdichado" (2015, p. 109).

46 | AlPha No49 (DicIEMBRE 2019) PÁGS. 39-56. ISSN 07 16-4254
} 
para con sus sirvientes y más bien los tildan con adjetivos peyorativos (Ginzburg, 2001, pág 4).

Los personajes pequeñoburgueses que trabajan por un salario son varios ${ }^{13}$. Es posible advertir una asociación entre melancolía, tedio y apatía política en la caracterización de los personajes de Caro Michele, así como indica nuestra hipótesis de análisis. Mientras el contexto político en el que la obra fue ambientada está atravesada por conflictos que involucran atentados de violencia política, resulta significativo que el silencio de la mayoría de los personajes pertenecientes a estratos medios respecto de la política en general, y a la militancia de Michele -obligado a huir como exiliado-expresa la indiferencia social que los engloba en común. Este silencio o apatía se puede vincular con lo que Siegfried Kracauer analiza en su monografía Los Empleados ${ }^{14}$ respecto de los estratos medios y la "proletarización de los empleados"15: un análisis que lo lleva a

\footnotetext{
${ }^{13}$ Este es el caso de Michele que intenta independizarse de su madre y realiza tareas de lavaplatos, pasea perros y da clases en Inglaterra; el de Osvaldo, el exmarido de Ada, que vende libros usados en un local de su tío y cuya monotonía lo agobia; Angélica, que realiza traducciones técnicas en una oficina y que se queja por la falta de sentido de sus tareas rutinarias y su marido Oreste, que trabaja por las noches en un periódico, con el que no está conforme; los Lillia prueban suerte con el comercio abriendo una fonda en Trapani y se enfrentan con numerosos problemas económicos; Mara realiza tareas domésticas en la casa de la familia Peroni, se ocupa de actividades administrativas en la editorial de Fabio Collarosa y finalmente trabaja en la fonda de los Lillia, todos trabajos a los que no logra adaptarse, ya que en numerosas ocasiones la echan y en otras renuncia.

${ }^{14}$ La monografía Los empleados. Un aspecto de la Alemania más reciente aparece en enero de 1930 en la Societät- Drückerei y había sido publicada previamente en Frankfurter Zeitung. Allí, Kracauer se propone analizar la situación de los empleados en la ciudad de Berlín de la República de Weimar, del modo más extremo, basándose en citas, conversaciones y observaciones realizadas in situ: "solo es posible acceder a la realidad a partir de sus extremos" (2008, p.105). Lo que busca en su trabajo es un diagnóstico que "renuncia a una propuesta de mejora", pero sí conlleva una voluntad de motivar una discusión pública de un tema que considera poco explorado para la época (2008, p. 106): "Centenares de miles de empleados pueblan a diario las calles de Berlín, y sin embargo su vida es menos conocida que la de las tribus primitivas" (2008, p.112).

${ }^{15} \mathrm{Su}$ argumento pertinente a la "proletarización de los empleados" alude al hecho que observa una esclavitud moderna cada vez menos protagonizada por una gran masa de obreros sino por los oficinistas, los que, a partir de un proceso de racionalización imparable, inherente al capitalismo mismo, acentuado con la instalación de las máquinas y de las cadenas de montaje según el modelo norteamericano, permiten que una multitud de empleados - cualificados y no cualificados- cumplan tareas mecánicas que los llevan a ser como soldados de "un ejército, en cuyas filas surgen cada vez más hombres corrientes, que son intercambiables entre s'́" y cuya existencia está condicionada por la inseguridad de los despidos, los bajos salarios y la falta de perspectivas de independencia (2008, págs. 114-115). Es por eso que, Kracauer cuestiona la ilusión de los empleados mismos, que al considerarse como una "nueva clase media" (2008, p.115), que con un sueldo bajo procura, de todos modos, empaparse del brillo de una vida social dictado por la moda y los objetos de consumo. Esto les otorga la apariencia de pertenecer a la burguesía y los mantiene contentos (2008, págs. 114-115). De hecho, Kracauer considera que estos estratos "se nutren de una falsa conciencia" y que "profesan un individualismo que solo poseería un fundamento si aún pudieran configurar sus destinos como individuos" (2008, p.194). De esta manera, él indica que la diferencia entre el proletariado y los empleados se basa en el hecho de que estos últimos están "espiritualmente desamparados", y postula que dados los cambios en el proceso de producción los 
concluir que el desamparo espiritual y el individualismo son una de las características predominantes de los estratos medios que trabajan como empleados de comercio y oficinistas, a los que compara con soldados de un ejército, por su capacidad de ser intercambiables entre sí y cuya identificación con la burguesía, en oposición con la del proletariado, supone la profesión de una falsa conciencia y un miedo a interrogarse a sí mismos (Kracauer, 2008, pp.114-115). La afinidad entre los personajes de Ginzburg pertenecientes a la pequeña burguesía y la caracterización de los estratos medios de Berlín en la República de Weimar que analiza Kracauer, encuentra una consonancia, más allá de la distancia temporal y la diferencia de contexto, en lo que respecta a sus actitudes vinculadas a un conservadurismo propio de las clases medias, cuya identificación con la burguesía da lugar a un desprecio por el proletariado, por las causas sociales, por la militancia en general y se propone, en cambio, conservar y reproducir el statu quo.

\section{AMBIGÜEDADES EN LA MILITANCIA DE MICHELE}

Es posible rastrear, en particular en los discursos de Adriana y de Ada, un desprecio por la militancia y por la política en general, que si bien varios personajes comparten, ellas explicitan de un modo más directo. Su condena hacia el compromiso político de los jóvenes, a los que asocian con la vagancia resulta sintomática de este discurso. Las consideraciones de Ada y de Adriana hacia la militancia, como una actividad que les parece improductiva, se identifican con la defensa de los valores pequeñoburgueses y con el conservadurismo. Como indica Ada sobre Michele y Mara, dos jóvenes a los que cuestiona por llevar una vida desordenada, sin horarios de trabajo, sin casa, ni familia, en los márgenes de un sistema en el que no se pueden insertar: "El mundo ahora está lleno de estos chicos, que giran sin un propósito de un lugar al otro. No se puede entender cómo envejecerán"16 (Ginzburg, 2001, p.54).

Si bien el viaje de Michele es un exilio político, no hay indicios claros acerca de este tema en la novela. Su militancia se presenta al lector de un modo oblicuo y cambiante. A su madre le oculta que milita y le dice que se va a Inglaterra para dedicarse a la escultura, aunque ella sospecha que se trata de una fuga y pregunta por su posible cercanía a grupos políticos, para ella, peligrosos: "Le pregunté si por casualidad tú no habías acercado a grupillos políticos peligrosos. Tengo siempre un miedo tremendo que tú puedas terminar con los tupamaros" ${ }^{17}$ (Ginzburg, 2001, p.25). En cambio, a su hermana

\footnotetext{
antiguos sentimientos burgueses que habían habitado esa masa se habrían derrumbado y su existencia estaría condicionada por una falta de metas y un miedo a interrogarse a sí mismos (2008, p. 205).

16“'Il mondo ora è pieno di questi ragazzi, che girano senza scopo da un posto all'altro. Non si riesce a capire come invecchieranno.

17، Gli ho chiesto se per caso tu non avevi avvicinato gruppuscoli politici pericolosi. Ho sempre una paura tremenda che tu possa finire nei tupamaros".
}

48 | AlPha No49 (Diciembre 2019) PÁGs. 39-56. ISSN 07 16-4254 
Angélica le confiesa haber partido porque habían arrestado a un amigo suyo, le pide que se deshaga de un rifle que se había olvidado en un escondite de la estufa de su casa y también acude a ella en busca de ayuda para alojar a su amigo militante Ray.

Cuando Michele se muda a Inglaterra, según sus cartas sabemos que se desvincula de la política y de sus amigos militantes de Roma y al mismo tiempo se casa con una mujer inscripta al Partido Comunista: "Yo sigo sin ser comunista, sigo sin ser nada, y perdí contacto con los amigos que tenía en Roma y no sé más nada de ellos"18 (Ginzburg, 2001, p.100). Más allá de la falta de claridad en relación con la filiación política de Michele y por los cambios de rumbo que experimenta en la novela, desde el entusiasmo hasta el alejamiento de la militancia, este personaje experimenta una oscilación constante entre el compromiso y el desinterés por lo político.

Un rol significativo de desenmascaramiento del conservadurismo de las clases medias lo asume el personaje de Mara Castorelli, así como señala el análisis de Iacoli (2008, pp.72-73), que indica cómo su papel de nómada en distintas casas testimonia un malestar que le permite observar hipercríticamente los objetos y las personas que la rodean con una sinceridad extrema. Mara es una figura marcada por varias dificultades como la falta de una vivienda, de un trabajo y acude a sus amigos en busca de ayuda. Su vitalidad y sus aseveraciones irónicas son puestas en un primer plano en las situaciones más dramáticas: "soy desgraciada con todo"19, le dice a Osvaldo (Ginzburg, 2001, p.16). Ella sostiene que se siente más cómoda contando mentiras que diciendo la verdad, con el objetivo de esconder sus desgracias. Sin embargo, esta declaración resulta irónica, ya que justamente en toda la obra la palabra de Mara es la que cumple un papel de denuncia de lo que los otros personajes ocultan: "estaba cansada de darle pena. Uno se cansa de darle pena a la gente. Luego, algunas veces estamos tan caídos que la única manera de sentirnos mejor es inventar mentiras"20 (Ginzburg, 2001, p.21). Mara cumple la función de ridiculizar la realidad con humor y de revelar el descontento de los personajes pequeñoburgueses con los que se relaciona; comparte con Michele el nomadismo y la discrepancia con su entorno. A su vez, la hermana de Michele, Angélica, es el único personaje que parece comprender el sufrimiento de Mara y el silencio de Michele, ambos outsiders en la trama y disconformes con el entorno social que los rodea.

\footnotetext{
18“" Io continuo a non essere comunista, continuo a non essere niente, e ho perso i contatti con quelli amici che avevo a Roma e non so piú niente di loro".

19“'[S]ono disgraziata con tutto".

20، Ero stufa di farle pena. Uno si stufa di fare sempre pena alla gente. Poi certe volte siamo cosí a terra che l'unico modo di sentirsi meglio è inventare balle".
}

ALPHA No 48 (JULIO 2019) PÁGS. 39-56. ISSN 07 16-4254| 49 


\section{MELANCOLÍA Y CREACIÓN ARTÍSTICA}

Es posible explorar la relación antes abordada entre melancolía y genio creativo a raíz de las expresiones artísticas de los personajes de Caro Michele. Uno de ellos lo encarna el padre de Michele, un pintor, que el lector conoce mediante las descripciones que hacen de él las cartas de su exmujer, Adriana, y a partir de los recuerdos de Angélica evocados por el narrador. Siente rechazo por casi todas las personas que lo rodean, salvo por Michele, su único hijo varón, al que se lleva a vivir consigo desde pequeño, luego de separarse. El padre se enferma del estómago y muere pocos días después de la partida al exterior de Michele, que no vuelve de Inglaterra para su funeral. Él idealiza a su hijo pero, paradójicamente, no lo conoce en absoluto, ya que Michele fue criado por la cocinera. El padre es presentado por su hija Angélica como una figura triste:

Él caminaba con sus pasos largos, las dos manos en los bolsillos, sus largos flecos negros desordenados, la corbata mal puesta, el saco de alpaca negro como siempre muy arrugado y gastado, el rostro moreno y grande con su grande boca siempre amarga y disgustada ${ }^{21}$ (Ginzburg, 2001, p.31).

La descripción del retrato de Adriana pintado por el padre es también representativa de la tristeza y tiene algunas semejanzas con la figura meditabunda del grabado de Alberto Durero Melancolía I, ya que se trata de una persona contemplativa y triste con las manos en el mentón:

Se veía a la madre en una ventana, con las manos entrelazadas debajo del mentón. Llevaba un saco a rayas blancas y azules. Sus cabellos eran una nube rojo-fuego. Su rostro era un triángulo seco, burlón y lleno de surcos. Sus ojos eran pesados, despreciativos y lánguidos ${ }^{22}$ (Ginzburg, 2001, p.32).

Las pinturas del padre adoptan la técnica del "amontonamiento"23, con la que se superponen imágenes que fluctúan: "En los últimos tiempos, se había puesto a hacer cuadros enormes, en los que superponía cada especie de cosas. [...] Fluctuaban en una luz verde barcos, automóviles, bicicletas, petroleros, muñecas, soldados, cementerios,

\footnotetext{
21 "Egli veniva avanti con i suoi passi larghi, le due mani in tasca, i lunghi ciuffi neri scompigliati, la cravatta che svolazzava, la giacca di alpaga nera come sempre molto spiegazzata e sgualcita, la bruna e grande faccia con la grande bocca sempre amara e disgustata".

22 "Si vedeva la madre a una finestra, con le mani intrecciate sotto il mento. Portava una maglia a righe bianche e azzurre. I capelli erano una nuvola rosso-fuoco. Il viso era un secco triangolo, beffardo e pieno di solchi. Gli occhi erano pesanti, sprezzanti e languidi".

${ }^{23}$ affastellamento.
}

50 | AlPha No49 (DiCIEMBRE 2019) PÁGS. 39-56. ISSN 07 16-4254 
mujeres desnudas y animales muertos"24 (Ginzburg, 2001, p.32). Los adjetivos con los que se define a las pinturas del padre son: trágica, solemne, gigantesca y minuciosa (Ginzburg, 2001, p.32). A su vez, las pinturas de Michele también tienen un elemento trágico como las de su padre, ya que se remiten a casas que se desmoran y a búhos. Es posible identificar una semejanza entre Michele y su padre debido a que ambos comparten una visión melancólica que encierra una crítica del escenario social que los circunda.

En la novela, se evoca la costumbre del padre, durante la infancia de Angélica, de cantar una canción de la resistencia española mientras pintaba: "No teníamos ni cañones | ni tanques ni aviones | oh Carmelà"25 (Ginzburg, 2001, pp.32-33), cuya alusión política puede referirse a su simpatía, en su juventud, con la resistencia española. Es por medio de esta figura que se manifiesta la representación de un compromiso político que responde al orden del pasado, un recuerdo que forma parte de la infancia evocada por Angélica junto a su padre y que es presentado como algo banal, pero que da cuenta de una pasión perdida, rescatada por la memoria en un clima de intolerancia, desgano y apatía política de los familiares de Michele.

La soledad y la tristeza cristalizadas en el padre y en Michele, como marcas de una melancolía, en la que pueden verse destellos de una "conciencia de uno mismo intensificada", se presentan de una manera opaca (Klibansky, Panofsky, y Saxl, 1991, pp.229-230). Es posible pensar que las cualidades artísticas de estos personajes responden a un carácter contemplativo "en el que el alma disfruta de su aislamiento, pero por ese mismo placer vuelve a tomar mayor conciencia de su soledad, 'la alegría en el dolor', 'la luctuosa alegría' o 'el triste lujo de pensar"' (Klibansky, Panofsky, y Saxl, 1991, p.229). El aislamiento del padre respecto del mundo que lo circunda, en el que solo hay lugar para una confianza ciega en su hijo Michele, encierra un enfoque pesimista y plagado de cuestionamientos ligados a la dimensión crítica que la melancolía adquiere en la obra. ¿Qué es lo que Michele mismo representa para el padre? ¿La fe en una juventud perdida? ¿La veneración por sus ideales políticos evocados detrás del canto de la resistencia española? ¿El interés compartido con Michele por la pintura y por la política? Todos estos interrogantes se abren en la narración y quedan abiertos, ya que no se presentan en la novela ni diálogos directos ni un intercambio de cartas entre Michele. La obra omite indicios explícitos que le permitan al lector comprender a estos personajes de manera acabada.

\footnotetext{
24 "Negli ultimi tempi, egli si era messo a fare dei quadri enormi, dove affastellava ogni specie di cose.[...] Fluttuavano in una luce verdognola navi, automobili, biciclette, autobotti, bambole, soldati, cimiteri, donne nude e animali morti".

25" Non avemo ni canones | ni tanks ni aviones | oi Carmelà"
} 


\section{MELANCOLÍA, TEDIO Y CONTEMPLACIÓN DE LAS MEMORIAS}

Es posible encontrar un vínculo entre la melancolía y el tedio que sufren los personajes de Caro Michele y la insatisfacción que sienten en relación con la monotonía de sus vidas y al agobio por sus trabajos repetitivos y alienantes. Algunos personajes, como Adriana, Osvaldo y Angélica, se refugian en la nostalgia y les atribuyen una importancia significativa a las memorias de sus vidas, otros como Michele y su padre canalizan su melancolía por medio del arte. Adriana es conocida por el lector por las extensas cartas que le dirige a su hijo Michele. En la narración, está relegada al ámbito del hogar y tiene a cargo a sus hijas gemelas adolescentes. Se destaca la relación con la melancolía de las dos lecturas que Adriana menciona. La primera son los Pensamientos de Pascal, lo que remite a la melancolía de la duda, la aflicción del hombre meditabundo que duda, entre la verdad del conocimiento de la ciencia y la verdad divina. La segunda lectura es de Proust, lo que pone en un primer plano la nostalgia por el tiempo de la infancia y la recuperación de los recuerdos mediante la memoria y la escritura. Otra intertextualidad literaria en la obra ligada a la melancolía es la del libro que Osvaldo le envía como regalo de casamiento a Michele: Las flores del mal de Charles P. Baudelaire, obra cuya vinculación con la tradición literaria de la melancolía no necesitamos exponer.

Adriana en detalladas cartas dirigidas a Michele intenta revisar no solo sus pensamientos, sino también los de su hijo, al que, al igual que el padre, apenas conoce. Sus cartas se caracterizan por tener un carácter introspectivo, con una manifestación recurrente de la nostalgia, debido a los constantes intentos de realizar una reconstrucción de su pasado. Por ejemplo, uno de los recuerdos que evoca como particularmente feliz es el de la última tarde que había visto a Michele, cuando había ido a su casa a buscar una alfombra sarda. Y admite que es raro reconocer los momentos felices mientras se los está viviendo, pues sostiene que se reconocen en general solo a distancia del tiempo (Ginzburg, 2001, pp. 125-126). La nostalgia de Adriana también se cristaliza en objetos, como la alfombra sarda antes mencionada y una estufa alemana amurada a la pared que le compra a Michele cuando se muda al sótano de Osvaldo. Esta estufa adquiere una carga simbólica: remite al calor del hogar, rechazado por su hijo, pero también a un ámbito político y a la diferencia ideológica que lo separa de su madre, ya que allí Michele esconde un fusil.

El pesimismo de Adriana se acentúa en las últimas cartas en las que se queja por

la falta de comunicación con su hijo Michele y por no conocerse en absoluto. Ella pronuncia constantemente aseveraciones cargadas de angustia y desconsuelo: "Te abrazo y te deseo felicidad, siempre que la felicidad exista, cosa que tal vez no se puede excluir 
del todo, aunque raramente vemos sus indicios en el mundo que se nos ha ofrecido"26 (Ginzburg, 2001, p.95). Otra señal del carácter melancólico de Adriana es que dice amar la tristeza: "Tal vez es por eso que me acostumbré a su compañía. Porque amo la tristeza. Amo la tristeza todavía más que la inteligencia"27 (Ginzburg, 2001, p.125).

Como se señaló anteriormente, Osvaldo acompaña a Adriana en las lecturas de Proust y, como ella, también se identifica con la melancolía que supone una afección del tiempo, el duelo por querer recuperar las experiencias que perecieron, pero sobre las que se retorna, para hacerlas sobrevivir a su muerte. Como Adriana, también considera importante la conservación de la memoria. Luego de la muerte de Michele, viaja a visitar los últimos lugares en los que su amigo había vivido en Inglaterra, realiza preguntas a sus conocidos y observa los objetos que había dejado allí. En la última carta que escribe se destaca su reflexión acerca de su capacidad, junto con la de Angélica y Adriana, de cultivar la memoria y de identificar en el momento presente los instantes de esplendor, dignos de ser recordados (Ginzburg, 2001, p.155-156). Tanto Adriana como Osvaldo, cierran el relato con una actitud pesimista y de incomprensión respecto del golpe que la muerte de Michele les genera. Osvaldo también siente pena por la falta de predisposición de Michele y de la juventud en general para mirar hacia atrás. Es por ello que se imagina que Michele antes de morir habría conocido y recorrido todos los caminos de la memoria (Ginzburg, 2001, p.156).

\section{CONCLUSIONES}

El vínculo entre la apatía política y la melancolía en esta obra, como mencionamos antes, permite problematizar un escenario atravesado por el tedio y por la alienación de sus personajes, de los que destacamos, por un lado, la actitud crítica que se desprende de la melancolía como proceso de desenmascaramiento de la falsa conciencia de la pequeña burguesía, encarnada por personajes como el padre, Michele y Mara. Por otro lado, ocupa un lugar destacado en Caro Michele un carácter testimonial de la obra en la que el silencio y la indiferencia respecto del conflicto de violencia política del contexto histórico en el que se posicionan la mayoría de los personajes, expresa un conservadurismo de las clases medias. Irónicamente, hasta el mismo Michele, el único personaje involucrado en la militancia, obligado a exiliarse por motivos políticos y que es asesinado por grupos neofascistas en una manifestación estudiantil en Brujas, brinda muy poca información al lector acerca de sus filiaciones políticas. Por el contrario, en sus breves cartas, solo una vez menciona su incapacidad para identificarse con el Partido Comunista, pero no aclara

\footnotetext{
26، Ti abbraccio e ti auguro felicità, ammesso che la felicità esista, cosa che forse non è del tutto da escludere, anche se raramente ne vediamo traccia nel mondo che ci è stato offerto".

27 "Forse è per questo che mi sono abituata alla sua compagnia. Perché amo la tristezza. Amo la tristezza ancora di piú dell'intelligenza".
} 
los motivos (Ginzburg, 2001, p.100). Como dijimos anteriormente, el lugar oblicuo que ocupan el silencio y la política como un objeto de deseo perdido en la obra se puede considerar afín a las reflexiones repecto del tedio en las grandes ciudades que brinda Kracauer antes mencionadas en Los empleados, cuyo antecedente se puede rastrear en el ensayo "Los que esperan" 28 . En dicho ensayo se aborda el sentimiento de soledad de las grandes ciudades que invade a las clases medias:

cuando [estas] se retiran desde la superficie al centro de su ser, les sobrecoge la profunda tristeza que libera la conciencia de su cautiverio en una determinada situación espiritual y que, finalmente, cubre por entero todos los estratos de su ser"29 (Kracauer, 2006, p.141).

A su vez, Vedda ha señalado que en este ensayo radicaría una reflexión de Kracauer pertinente a la figura del intelectual moderno "regido por un relativismo llevado al extremo":

desprovisto de certidumbres absolutas, el intelectual de la Modernidad (tardía) solo puede responder a las exigencias que su tiempo le plantea manteniendo -como conciencia desgarrada- un permanente estado de atención sobre sí mismo: revisando permanente sus propias convicciones y, ante todo, interrogándose por su lugar y función y lugar dentro de la vida social $(2011$, p. 20).

Dicha postulación de la conciencia desgarrada del intelectual moderno, ligada a la interrogación constante sobre sí mismo y sobre su función en la vida social implica para

\footnotetext{
${ }^{28}$ Publicado el 12 de marzo de 1922 en Frankfurter Zeitung.

${ }^{29}$ Mientras Kracauer describe dos caminos posibles para encontrar un refugio ante la falta de sentido que cobra la vida espiritual en las urbes capitalistas (uno vinculado al "aturdimiento" y a la "irreal existencia de sombras hechas de distracciones" y el otro en la subyugación dada por "una fe auténtica sin caer en la tentación de hacerse partícipes de niveles superiores de la realidad", también ejemplifica tres posibles clases de conducta. La primera, basada en el escepticismo por principio, cuyo ejemplo encuentra en Max Weber, la caracteriza por un impulso "a luchar por el "desencantamiento del mundo" y considera que "su existencia culmina en la mala infinitud del espacio vacío". El autor de Los empleados considera esta conducta como heroica, no ingenua y más cercana a la salvación. La segunda posición a la que llama "la de los hombres-cortocicuito" la caracteriza como una vía de escape a un "estuche salvador". Dicho escape no estaría apoyado en la fe, sino en la "voluntad de fe", que penetra en la esfera religiosa "de manera artificiosa", es decir, a partir de un "involuntario autoengaño". La tercera posición que describe es "la actitud de la espera", basada en el "vacilante estar abierto en un sentido, en todo caso, difícil de explicar", que tiene en común con el intelectual desesperado la valentía de la perseverancia y que implica, por un lado, no dejarse engañar por la necesidad religiosa y cuya fe "no sería concitada mágicamente, pero tampoco excluida". Para Kracauer, el rasgo particular de este tipo de posición se orienta en el intento de "instalarse en el mundo de la realidad y de las esferas que circunda" y de "trasladar el centro de gravedad desde el yo teorético al yo humanamente completo" (Kracauer, 2006, pp.149-156).
} 
Kracauer una actitud de observación detallada de la realidad y una disposición melancólica ligada al desenmascaramiento. De la mano de esta actitud, es posible analizar la función crítica de la melancolía en Caro Michele, que pone a la luz lo que se oculta detrás del tedio y de la apatía política de los protagonistas pequeñoburgueses de la obra.

A modo de cierre, este trabajo se enfocó en analizar los diferentes aspectos por los que se puede indagar, en Caro Michele, una puesta a la luz acerca del vínculo entre la melancolía y la pérdida de la esencia genérica humana en la vida cotidiana bajo el capitalismo; la propuesta de destacar su cristalización en el silencio y en la apatía política de sus personajes permite analizar la función crítica de desenmascaramiento de la hipocresía pequeñoburguesa que la melancolía cumple en la novela. De hecho, a la militancia titubeante e indecisa de Michele, a la que le sigue su asesinato en una manifestación durante su exilio político, se le opone la indiferencia de los personajes pequeñoburgueses con los que se vincula: un indicio político de la narración que refuerza el tono de denuncia de una obra, cuyo contexto es el de las luchas silenciadas en una urbe moderna: Roma en los años setenta en Italia.

\section{OBRAS CITADAS}

Borri, Giancarlo (1999). Natalia Ginzburg. Rimini: Luisè.

Buck-Morss, Susan (1995). Dialéctica de la mirada. Traducción de Robotnikof, N. Madrid: Antonio Machado.

Clementelli, Elena (1977). Invito alla lettura di Natalia Ginzburg. Milán: Mursia.

Crainz, Guido. (2016). Storia della repubblica. L'Italia dalla Liberazione ad oggi. Roma: Donzelli.

Ginzburg, Natalia (2014) [1963]. Lessico famigliare. Introducción de Segre, C. Turín: Einaudi.

(2011) [1977]. Famiglia. Scarpa, D. (ed.).Turín: Einaudi.

(2003) [1961]. Le voci della sera Introducción de Calvino, I. Turín: Einaudi.

(2002) [1970]. Mai devi domandarmi. Introducción de Garboli, C. Turín: Einaudi.

- (2001) [1973]. Caro Michele. Introducción de Garboli, C. Turín: Einaudi.

(1997) [1984]. La città e la casa. Turín: Einaudi.

- (1996) [1952]. Tutti i nostri ieri. Introducción de Magrini, G. Turín: Einaudi.

(1994) [1983]. La famiglia Manzoni Turín: Einaudi.

(1974) [1974]. Vita immaginaria. Milán: Mondadori.

Klibansky, Raymond, Panofsky, Erwin y Saxl, Fritz (1991). Saturno y la Melancolía:

Estudios de Historia de la naturaleza, la religión y el arte. Traducción de Balseiro, M. L. Madrid: Alianza. 
Kracauer, Siegfried (2008). Los empleados. Un aspecto de la Alemania más reciente. Traducción, notas y posfacio de Vedda. M. Introducción de Belke, I. Prólogo de Benjamin, W. Barcelona: Gedisa.

— (2006). "Los que esperan". En S. Kracauer. Estética sin territorio. Edición y traducción de Jarque, V. Valencia: Murcia 141-156.

Marx, Karl (2015). Manuscritos económico-filosóficos de 1844. Introducción, traducción y notas Aren, F., Rotemberg, S. y Vedda, M. Buenos Aires: Colihue.

Mauro, Walter. (1986). "Walter Mauro parla con Natalia Ginzburg”. En Grignani, M. A., Luti, G., Mauro W., Sanvitale, F. Natalia Ginzburg: la narratrice e i suoi testi. Urbino: La Nuova Italia scientifica.

Peja, Laura (2009). "Natalia Ginzburg: il cavallo di troia. Allegria e ponderosa e lieve per un teatro della responsabilità". En Strategie del comico. Franca Valeri, Franca Rame, Natalia Ginzburg. Florencia: Le lettere, 127-184

Puppa, Paolo (1986). “Caro Michele, ovvero l'epistolario dal nulla”. En Grignani, M. A., Luti, G., Mauro W., Sanvitale, F. Natalia Ginzburg: la narratrice e i suoi testi. Urbino: La Nuova Italia scientifica, 107-111.

Sanvitale, Francesco (1986). "I temi della narrativa di NG: uno specchio della societá italiana”. En Grignani M. A., Luti, G., Mauro, W., Sanvitale F. (Eds.) Natalia Ginzburg: la narratrice e $i$ suoi testi. Urbino: La Nuova Italia scientifica (25-30).

Vedda, Miguel (2012) "Melancolía, transitoriedad, utopía. Sobre Origen del Trauerspiel alemán", En Benjamin, Walter. Origen sobre el trauerspiel alemán. Buenos Aires: Gorla.

_ (2011). La irrealidad de la desesperación. Estudios sobre Siegfried Kracauer y Walter Benjamin. Buenos Aires: Gorla. 